\title{
Introduction
}

\section{Untimely Mourning: Representing Child Death and Parental Mourning in Contemporary French and Francophone Literature and Culture}

\begin{abstract}
Il n'y a donc pas de métalangage quant au langage où s'engage un travail de deuil. C'est aussi pourquoi on ne devrait rien pouvoir dire du travail de deuil, rien dire à son sujet puisque cela ne peut pas devenir un thème, seulement une autre expérience du deuil venue travailler au corps de qui entend parler. ${ }^{1}$
\end{abstract}

Jacques Derrida

No matter when the loss of a child happens, from infancy through to adulthood, whether it is unexpected or not, representing child death raises the question of an ethics of parental mourning - the uniqueness of this grief, its almost unspeakable nature and its traumatic consequences. Parents expect to be able to protect their child(ren), to outlive them, but the loss of a child shatters this illusion. Seen as a disruption of the natural order, the death of a child forces parents into a difficult, and sometimes impossible, process of reconstruction. In France, as in most other Western countries, grief and mourning tend to be confined to the private sphere, with a few notable exceptions: the last decades saw open displays of grief upon the death of public figures; ${ }^{2}$ large public gatherings in reactions to

1. Jacques Derrida, Chaque fois unique, la fin du monde, ed. by Pascale-Anne Brault et Michael Naas (Paris: Galilée, 2003), p. 178.

2. As seen with the unexpected death of Diana, Princess of Wales in Paris in 1997; more recently with the hommage populaire to popular singer Johnny Hallyday who died in 2017. 
terrorist attacks; ${ }^{3}$ and marches blanches organized in reaction to the death of children in shocking circumstances such as paedophilia, abduction, and/or murder. ${ }^{4}$ Most of the time, however, the death of a child and its aftershocks remain highly personal matters. In an era when infant and child death have become a rare occurrence, when death is often medicalized, when the stages following someone's passing have to obey administrative and cultural protocols, expressing parental grief can be seen as an assault against the social order. Mourning parents know that their circumstances are unusual, almost indecent; they know that the wider community, as well as their closest relatives, often do not know how to react to their grief. They are surrounded by set phrases asking them to aller de l'avant, faire son deuil, phrases which suggest that mourning should reach a point of completion. And yet, for many parents, mourning their child is not only an untimely process, it is also a never-ending one. ${ }^{5}$ In this context, it is interesting to notice that récits de morts, texts dealing with the passing of a loved one, have become quite widespread in French and Francophone culture, to the extent that they may be seen as a literary genre, or sub-genre, as suggested by Jacques Drillon. ${ }^{6}$ Child death is also widely represented on screen, via either invented stories, or plots based on real events. ${ }^{7}$ Could this suggest that artistic representations of child death and parental mourning may be a way to reach out to a broader community, to create a public space for the

3. Evidenced by the marche républicaine which took place in Paris and all over France after the Charlie Hebdo attacks of January 2015, totaling 3.7 million participants.

4. The term 'marche blanche' was used in 1996 in Brussels to remember the victims of notorious paedophile Marc Dutroux. It has been used broadly since to refer to silent marches organized to remember young victims of crimes, as seen in France in August 2018 in memory of Maëlys de Araujo, murdered the previous year.

5. A feeling echoed by many of the writers included in this special issue, and also by Philippe Forest, who has experienced the death of his young daughter and has written extensively about it, and about the mourning process. See in particular Tous les enfants sauf un (Paris: Gallimard, Folio, 2008 [Gallimard, 2007]).

6. Jacques Drillon, Face à face (Paris: Gallimard, 2003), p. 129.

7. See for instance the study by Emma Wilson, Cinema's Missing Children (London: Wallflower Press, 2003). 
expression and the representation of grief? What is the function of giving a written or visual form to experiences of loss? Is it to try to comprehend, to break a taboo, or is it to create a place for healing? This special issue focuses on an aspect of mourning which is, as yet, relatively unexplored in critical discourse, ${ }^{8}$ although it is wellrepresented in numerous recent artistic forms. As such, this special issue will provide an important addition to the current body of work examining grief and mourning in contemporary fiction, by focusing on parental grief.

Mourning and death are widely addressed in psychoanalysis and psychotherapy; they are also objects of anthropological, medical and psychological studies. Since Freud's seminal text 'Mourning and Melancholia', ${ }^{9}$ many psychoanalysts have analysed the process of mourning, offering theories of stages of mourning, ${ }^{10}$ some of them adopted by 'self-help' guides meant to help grieving families, such as the Handbook of Bereavement. ${ }^{11}$ In the latter text, although authors are careful to note that its content and analyses are not prescriptive, will the effects not be prescriptive? Will mourners not consult such guides and manuals to find out what they are 'expected' to be feeling? As many of the articles in this special issue suggest, it is difficult to apply phases of bereavement to artistic representations of parental mourning. This could be because parental mourning does not follow a

8. A very notable exception being Gill Rye's study, 'Family Tragedies: Child Death in Recent French Literature', in Affaires de famille: The Family in Contemporary French Culture and Theory, ed. by Marie-Claire Barnet and Edward Welch (Amsterdam: Rodopi, 2007), pp. 267-81.

9. Sigmund Freud, 'Mourning and Melancholia [1917]', in The Standard Edition of the Complete Psychological Works of Sigmund Freud, Volume XIV (1914-1916): On the History of the Psycho-Analytic Movement, Papers on Metapsychology and Other Works, pp. 243-58.

10. One of the best-known of these stage theories is the Kübler-Ross model, with the chronological stages of denial, anger, bargaining, depression and acceptance.

11. Margaret S. Stroebe, Wolfgang Stroebe, Robert O. Hansson, Handbook of Bereavement: Theory, Research, Intervention (Cambridge: Cambridge University Press, 1993) 
prescribed script and is almost always a 'deuil compliqué 12 which goes beyond set patterns of grieving and reconstruction. This is also because artistic representations have a different function to scientific (or pseudo-scientific) manuals: not only in that they tend to focus on the uniqueness of each experience of mourning, but also because they engage with its mise en mots, its complex relation with language and artistic expression. Many parents who have lost a child notice that they are faced with an aporia to express their circumstances: in French as in English, there is a word to refer to a child who has lost one, or both parents (an orphan / un.e orphelin.e); there is a word for someone who has lost their spouse (a widow.er / un.e veuf.ve). However, there is no word to refer to a parent who has lost a child. Should they be called orphaned parents? Or, as Sophie Daull suggests, 'morts vivants'? ${ }^{13}$ Or should their status remain nameless, to accentuate its position as something which seems, almost by essence, untellable? For Emma Wilson, the loss of a child is '[...] a limit subject, a subject which reaches or exceeds the bounds of representation, and normative, or narrative, resolutions. ${ }^{, 14}$

This special issue addresses the many facets of parental mourning, from the perspective of both mother and father, as well as its impact on their sense of identity, on the parental couple and its entourage. It also examines the linguistic, narrative and filmic strategies deployed to address this sensitive question. It suggests that constructing a narrative (whether from lived experience or from a fictional angle), finding the appropriate voice, or voices, reworking memories, creating a story, a structure, a testimony or a narrative, are essential to dealing with such traumatic events. As such, the various degrees of fictionalisation examined in this special issue confirm Kathryn Robson's remark that '[...] it may even be necessary to re-

12. Phrase used by Martine Lussier in Le Travail de deuil (Paris: Presses Universitaires de France (Collection 'Fil rouge'), 2007), p. 21.

13. Sophie Daull, Camille, mon envolée (Paris, Le livre de poche, 2016 [Philippe Rey, 2015]), p. 85.

14. Emma Wilson, Cinema's Missing Children, p. 153. 
imagine and fictionalise a traumatic past in order to survive and to deal with the past. ${ }^{15}$

The group of articles collected here offers close readings of a wide variety of contemporary French and Francophone texts, both written and visual, whose common focus is the narration of the experience of the death of a child from the parental perspective. In some cases the point-of-view is either exclusively maternal or paternal and in others the loss is examined from the position of the couple, or even viewed externally. The texts selected for analysis include autobiographical and fictional accounts. Yet, while they present a diverse range of narrative styles, there is a marked preference for intimate writing or the diaristic form which seems to be the most apposite mode for reflection on the very deep, personal and inner nature of the grief that is being voiced. In bringing together the articles for this collection, we were keen to offer as full and composite a discussion of the different forms of parental mourning as possible. In this respect, we have included death that occurs at different stages of the child's lifespan from premature and perinatal death right through to young adulthood. Furthermore, the articles engage with child deaths that were expected, prepared for, even 'desired' (see Holly Runde's article on grief following voluntary abortion) and others that arose suddenly and unpredictably (Julie Rodgers's contribution, for example). The cause of death in each text selected is similarly divergent, incorporating suicide, abrupt illness, longer-term disease, and even death that is never explained as is the case in Elise Hugueny-Léger's article dealing with the disappearance of a child whose body is never recovered. And yet in spite of the multiple variegations between the texts examined here, there are distinct convergences too in their treatment of child death and parental mourning, particularly in relation to its unspeakability and untellability. What emerges from all of the discussions is a clear sense

15. Kathryn Robson, Writing Wounds: The Inscription of Trauma in post-1968 French Women's Life-writing (Amsterdam: Rodopi, 2004), p. 25. 
that existing models of grief are wholly inadequate when it comes to the experience of losing a child. These articles demonstrate that parental mourning is a type of bereavement that is more akin to a trauma which the victim has to navigate on an enduring basis rather than an emotional disturbance that can be consolidated and overcome. Narrating the death of the child becomes a means then, not simply of finding words that can go some way to articulating the almost unfathomable nature of such a loss, but of creating an outward textual space where the absent-present child can continue to exist alongside the parent, thus perhaps providing some form of release for the inner torment of the bereaved parent. The parent who loses a child becomes an irremediably altered subject who now has to negotiate a certain 'afterwardness' of their parental identity that $\mathrm{s} / \mathrm{he}$ has not been prepared for.

The articles have been ordered so as to present a trajectory of sorts of parental bereavement, beginning with very early child death and concluding with the loss of older children. The first two contributions present us with what could arguably be the type of parental mourning that has least access to language and cultural imagination, that is, the death of the not-yet-child in the womb. Although Runde and Khalid Lyamlahy deal with two different types of intrauterine loss, one chosen through elected abortion (Runde) and the other spontaneous (Lyamlahy), what emerges from each is the ambivalence and liminality of both the mourned object and the mourning subject arising from this type of loss where the temporal proximity of birth and death is a key factor in shaping the experience. In these circumstances, the life of the child is suspended and the existence of the prospective parent interrupted. What remains is a feeling of in-betweenness for the parent and of simultaneous presence and absence in relation to the child. In his analysis of the novel L'Enfant de marbre by Mohamed Leftah (2007), Lyamlahy asks the pertinent question of how to mourn the death of a child that has not yet been and will not be born and, indeed, how to represent what could be possibly be described as a 'non-event' given that there was no live birth. For Runde, the challenge emerges from the fact that a 
woman who discontinues a pregnancy through abortion is not expected nor indeed permitted by society to mourn this loss given that she has voluntarily chosen it. When examining Louise Lambrichs's Journal d'Hannah (1993), Runde rejects the facile anti-feminist interpretation of the text as a diatribe against abortion and a testimony of inevitable regret. Instead, she asks us to consider the possibility and the need for a discursive space and representative realm where the prohibited mourning of women who abort through choice can be explored.

From single text studies, we then move on to comparative discussions of the death of a child in the contributions made by Barbara Havercroft and Kathryn Robson. We also leave behind loss during pregnancy and birth and advance a little further into the life cycle of the child with Havercroft's article dealing with the death of infant babies and Robson's focusing on young children. The shared focus of these articles is their specific concentration on language and grief, not simply in terms of how, when or even if a parent might ever be able to even articulate his or her loss, but, rather, the very particular forms that language might adopt in terms of rhetoric and style in the narration of such a traumatic event. Havercroft examines in detail the role of writing as part of the work of parental bereavement and reflects on the possibility of a poetics of mourning in Camille Laurens's Philippe (1995) and Laure Adler's À ce soir (2001). Related to this notion of a poetics of mourning is the idea of the text as an offering to the deceased child and the writing of the text itself as a performative and creative stage in the bereavement process which, although not definitive in its ability to heal the loss, at the very least facilitates verbal engagement with, and inscription of, the otherwise unspeakable suffering. Robson skillfully dissects Hélène Cixous's Le Jour où je n'étais pas là (2000) and Marie Darrieussecq's Tom est mort (2007) and teases out a definition of what one could term 'language after the end', signalling fragmentation, erasure and even incoherency as some of its key characteristics. Read alongside one another, these two contributions 
produce an intricate conceptualization of the very complex nature of the discourse of parental loss.

In the following three articles, we move towards the death of older children, the specificity of the paternal bereavement and a discussion of a cinematic representation of child loss through suicide. It is Adrienne Angelo and Máire Áine Ní Mhainnín who perceptively draw our attention to the paucity of studies on the experience of the death of a child from the perspective of the father. Angelo's contribution highlights the many societal and cultural expectations that hinder paternal mourning and often force the bereaved father into a position of repressed grief. To counter this silence, Angelo provides an attentive reading of four recent texts that prioritise the paternal voice and, furthermore, challenge and transgress the prescribed script of the father whose identity does not appear to be impacted by the loss of his child: Michel Rostain's Le Fils (2011), Alain Thiesse's Elle s'appelait Emma (2014), Philippe Delaroche's La Gloire d'Inès (2016), and Bernard Chambaz's À tombeau ouvert (2016). In concurrence with Angelo, Ní Mhainnín highlights the scarcity of texts that concentrate on, and comprehensively explore paternal grief. Ní Mhainnín redresses this balance by analysing the death of the 'other daughter' in the works of Annie Ernaux, and its impact on the father. In this respect, it is interesting to note that Ernaux's L'Autre fille (2011), while providing much insight into the father's experience, does so through the lens of the deceased child's sibling (the second daughter) rather than adopting the father's own voice. That the father's grief is observed and described, therefore, reinforces the point made by both Angelo and Ní Mhainnín that the mourning process of fathers requires increased critical consideration. A key point that emerges in Ní Mhainnín's article and which links neatly with Ben McCann's contribution is the notion of the haunted parent who is now physically and psychologically inhabited by the deceased child. In the case of McCann's article, this idea of haunting relates to the central couple in Guillaume Nicloux's film Valley of Love (2015), who have been brought together again after a long separation by their adult son who has recently committed suicide. As McCann notes, the film is 
replete with moments of the uncanny and the overarching spectral presence of the dead son as the parents attempt to make peace with both their loss and themselves. In a vein that is similar to Ní Mhainnín's use of Freud as a way to interpret the father's mourning, McCann maps the journey of this particular bereaved couple onto Colin Parkes's stages of grief.

The final two contributions that appear in this special issue are from the editors themselves, Hugueny-Léger and Rodgers. Both present the loss of a child in very unexpected and traumatic circumstances - disappearance (in Laurence Tardieu's fictional Puisque rien ne dure (2006) analysed by Hugueny-Léger), and sudden illness (in Sophie Daull's autobiographical account Camille, mon envolée (2015) discussed by Rodgers). The detrimental impact of the loss of a child on the life of a couple is a central idea in the two discussions, often leading to separation or, at the very least, emotional estrangement. However, in contrast to Angelo and Ní Mhainnín's focus on the specificity of paternal bereavement, here the authors turn towards the unique features of maternal grief. The mother becomes a physical incarnation of the lost child with her body exhibiting the symptoms of wounds (Rodgers) or, as Hugueny-Léger remarks, a living tomb that harbours the dead child within, similar, perhaps, to the previous duality of the womb during gestation. In the case of maternal grief, what is most notable in these contributions is the sheer viscerality of the bereavement (stemming from the fact that the mother gave birth to the child) which it would seem, differentiates it from (without belittling) paternal grief. However, it should be noted that in both of the texts selected for discussion by Hugueny-Léger and Rodgers, the deceased child in question is a daughter - an interesting echo with the plethora of established critical studies on the symbiotic nature of the mother-daughter relationship.

Finally, it is important to offer a few words about the choice of title for this special issue, 'Untimely mourning'. Death is almost always, unavoidably, perceived as untimely. Losing a loved one creates a break in the experience of time (there is a 'before' and an 'after') and always seems to happen 'too soon', whatever the 
circumstances. This is all the more striking, however, with unexpected deaths, which give rise to a form of trauma and a rupture in the perception of time. ${ }^{16}$ When a child dies, a sense of revolt emerges from the fact that this goes against the 'natural order'. Time is a highly subjective notion, and each mourning parent will experience differently the process, and pace, of mourning — some experiencing the urge to write about the event very quickly, others retreating into a long period of isolation and silence, others rushing to resume a 'normal life', others still deliberating whether or not to put the events into words years, or even decades, after their occurrence. No matter the circumstances, however, representing child death in film or literature can act as a way to create a timeless evocation which can be widely shared.

Elise Hugueny-Léger, University of St Andrews Julie Rodgers, Maynooth University

16. As analysed by Cathy Caruth in her essay Unclaimed Experience: Trauma, Narrative, and History (Baltimore: Johns Hopkins University Press, 1996.) 